\title{
CÁC YẾU TỐ ẢNH HƯởNG ĐẾN SỬ HÀI LÒNG CỦA KHÁCH HÀNG CÁ NHÂN ĐỐI VỚI CHẤT LỰ̛̣G DİCH VỤ TẠI NGÂN HÀNG THƯỜG MẠI CỔ PHẦN ĐẦU TƯ VẢ PHÁT TRIỂN VIỆT NAM - CHI NHÁNH BÌNH PHƯớC
}

\author{
LÊ THI KIM HOA ${ }^{1}$, ĐOÀN THÀNH LONG ${ }^{2}$, VÕ ANH KIẸT ${ }^{3}$ \\ ${ }^{1}$ Khoa Quản trị kinh doanh, Trường Đại học Công nghiệp thành phố Hồ Chí Minh \\ ${ }^{2} N g a ̂ n$ hàng Thuoong mại Cổ phần Đầu tư và phát triển Việt Nam - Chi nhánh Bình Phước; \\ ${ }^{3}$ Viện Khoa học Công nghệ và Quản lý Môi trường, Trường Đại học Công nghiệp thành phố Hồ Chí Minh \\ lethikimhoa@iuh.edu.vn
}

Tóm tắt. Hiện nay, trên địa bàn tỉnh Bình Phước có nhiều Ngân hàng đang hoạt động kinh doanh, các Ngân hàng này đều có sản phẩm dịch vụ rất đa dạng, phong phú và cạnh tranh vô cùng gay gắt. Tuy nhiên, việc nghiên cứu các yếu tố ảnh hưởng đến sự hài lòng của khách hàng cá nhân đối với chất lượng dịch vụ tại Ngân hàng Thương mại Cổ phần Đầu tư và Phát triển Việt Nam - Chi nhánh Bình Phước (BIDV - CNBP) còn mới mẻ. Nghiên cứu này được thực hiện thông qua phương pháp nghiên cứu định tính, nghiên cứu định lượng và được kiểm định bằng phần mềm ứng dụng SPSS 22.0. Mô hình được kiểm định gồm 5 yếu tố độc lập (với 21 biến quan sát) và 1 biến phụ thuộc (với 3 biến quan sát). Phương pháp chọn mẫu là ngẫu nhiên có phân tổ với số mẫu là 275 . Kết quả nghiên cứu cho thấy có 5 yếu tố ảnh hưởng đến sự hài lòng của khách hàng cá nhân đối với chất lượng dịch vụ tại BIDV - CNBP bao gồm: Sự tin cậy; Khả năng đáp ứng; Năng lực phục vụ; Sự đồng cảm; và Phương tiện hữu hình. Từ kết quả nghiên cứu, nhóm tác giả đã đề xuất 5 hàm ý quản trị nhằm nâng cao hơn nữa sự hài lòng của khách hàng cá nhân đối với chất lượng dịch vụ tại BIDV - CNBP.

Từ khóa. Sự hài lòng; Khách hàng; Chất lượng dịch vụ.

\section{FACTORS AFFECTING THE SATISFACTION OF INDIVIDUAL CUSTOMERS ON THE SERVICE QUALITY AT THE JOINT STOCK COMMERCIAL BANK FOR INVESTMENT AND DEVELOPMENT OF VIETNAM - BINH PHUOC BRANCH}

\begin{abstract}
Currently, there are many banks operating in Binh Phuoc province with diversification of banking services and fierce competition. However, the research of factors affecting individual customer's satisfaction on service quality at the Joint Commercial Bank For Investment and Development of Vietnam - Binh Phuoc Branch (BIDV - Binh Phuoc Branch) is still new. This research was conducted by qualitative and quantitative research methods and analyzed with SPSS 22.0. The research model was tested with 5 independent factors (consisting 21 observed variables) and 1 dependent variable (including 3 observed variables). Sampling was randomly stratified with 275 samples. The research results show that there are 5 factors affecting satisfaction of individual customers on service quality at BIDV - Binh Phuoc Branch including: Reliability; Responsiveness; Service capabilities; Empathy; and Tangibles. From the research results, the authors propose 5 administrative implications to further improve satisfaction of individual customers on the service quality at BIDV - Binh Phuoc Branch.
\end{abstract}

Keywords. Satisfaction; Customers; Service Quality.

\section{GIỚI THIỆU}

Ngày nay, các sản phẩm dịch vụ của các Ngân hàng trong nước không ngừng phát triển đáp ứng được nhu cầu của khách hàng trong thời kỳ hội nhập kinh tế với nhiều dịch vụ tài chính hiện đại. Hầu hết các Ngân hàng hiện nay đều đã và đang xem chiến lược phát triển khách hàng cá nhân là chiến lược quan trọng và định hướng trong tương lai [1].

Ngân hàng Thương mại Cổ phần Đầu tư và Phát triển Việt Nam (BIDV) là một trong những Ngân hàng thương mại tiên phong trong việc nghiên cứu, xây dựng các sản phẩm/gói sản phẩm, dịch vụ tài chính tốt nhất [1]. Với các sản phẩm dịch vụ đang triển khai, BIDV không ngừng nghiên cứu, cải tiến nhằm đưa ra các sản phẩm dịch vụ mới, các sản phẩm dịch vụ tốt nhất đáp ứng nhu cầu khách hàng. Những thành tựu 


\section{CÁC YẾU TỐ ẢNH HƯỞNG ĐẾN SƯ HÀI LÒNG CỦA KHÁCH HÀNG CÁ NHÂN ĐỐI VỚI CHẤT LƯỢNG DICCH VỤ TẠI NGÂN HÀNG TMCP ĐẦU TƯ VÀ PHÁT TRIẾN VIẸTT NAM - CHI NHÁNH BÌNH PHƯỚC}

có thể kể đến như "Ngân hàng Bán lẻ tốt nhất Việt Nam" lần thứ năm liên tiếp do The Asian Banker trao tặng; "Ngân hàng có dịch vụ chấp nhận thẻ và quản lý dòng tiền tốt nhất Việt Nam 2019" do BIDV có thành tích xuất sắc trong lĩnh vực dịch vụ tài chính bán lẻ [2].

Trong môi trường cạnh tranh như hiện nay, khách hàng chính là yếu tố quyết định sự tồn tại và phát triển của Ngân hàng. Vì thế, với định hướng chiến lược Ngân hàng bán lẻ, BIDV hướng đến việc tập trung nguồn lực để thực hiện mục tiêu nâng cao chất lượng dịch vụ, hoàn thiện và phát triển các sản phẩm, hướng tới làm thế nào để đem đến cho khách hàng sự hài lòng và thoả mãn khi sử dụng dịch vụ [3].

Vì vậy, việc nghiên cứu để đánh giá về chất lượng dịch vụ của BIDV - CNBP là vô cùng cần thiết, qua đó có thể tìm ra được các yếu tố ảnh hưởng đến chất lượng dịch vụ nhằm thoả mãn sự hài lòng của các khách hàng cá nhân trong thời gian tới.

\section{CỞ SỞ LÝ THUYẾT VÀ PHƯƠNG PHÁP NGHIÊN CỨU}

\subsection{Chất lượng dịch vụ}

Theo Lewis \& Mitchell (1990), chất lượng dịch vụ liên quan đến khả năng dịch vụ đó đáp ứng nhu cầu hoặc kỳ vọng của khách hàng [4]. Theo Advardsson và cộng sự (1994), cho rằng chất lượng dịch vụ là dịch vụ đáp ứng được sự mong đợi của khách hàng và là nhận thức của họ khi đã sử dụng dịch vụ [5].

Theo Parasuraman (1985), "Chất lượng dịch vụ được xác định bởi sự khác biệt giữa sự mong đợi của khách hàng về dịch vụ và đánh giá của họ về dịch vụ mà họ nhận được" [6]. Parasuraman đưa ra mô hình năm khoảng cách và năm thành phần chất lượng dịch vụ, gọi tắt là Servqual, Servqual được ghép từ 2 chữ "Service" và "Quality" và được nhiều nhà nghiên cứu đánh giá là khá toàn diện [7]. Sau đó, Servqual tiếp tục được hoàn thiện thông qua việc tập trung vào khái niệm về "Sự cảm nhận chất lượng"của người tiêu dùng, vì sự cảm nhận chất lượng của khách hàng là việc đánh giá có tính khách quan nhất về chất lượng của dịch vụ.

\subsection{Sự hài lòng của khách hàng}

Theo Phillip Kotler (2007), sự hài lòng của khách hàng là mức độ trạng thái cảm giác của một người bắt nguồn từ việc so sánh kết quả thu được từ việc tiêu dùng sản phẩm/dịch vụ với những kỳ vọng của mình. Mức độ hài lòng phụ thuộc vào sự khác biệt giữa kết quả nhận được và kỳ vọng, được xem xét dựa trên ba mức độ sau: Không hài lòng (khi mức độ cảm nhận khách hàng thấp hơn mong đợi); Hài lòng (khi mức độ cảm nhận khách hàng bằng mong đợi); Rất hài lòng (khi mức độ cảm nhận khách hàng cao hơn mong đợi) [8].

Theo Brown và cộng sự (1992), sự hài lòng của khách hàng là một trạng thái trong đó những gì khách hàng cần, muốn, mong đợi ở những sản phẩm/dịch vụ được thỏa mãn hay vượt quá sự thỏa mãn, kết quả là có sự mua hàng lặp lại, lòng trung thành và giá trị của lời truyền miệng một cách thích thú [9].

\subsection{Các nghiên cứu trước đây về sự hài lòng của khách hàng cá nhân đối với chất lượng dịch vụ của ngân hàng}

Một số nghiên cứu ở nước ngoài: Nghiên cứu của Snehalkumar H Mistry (2013) đo lường sự hài lòng của khách hàng trong ngành ngân hàng: Tài liệu tham khảo đặc biệt cho Ngân hàng Thành phố Surat gồm 5 yếu tố: Độ tin cậy, khả năng đáp ứng, đảm bảo, đồng cảm và phương tiện hữu hình [10]; Nghiên cứu của Anas Salman Alabboodi (2018) về Ânh hưởng của sự hài lòng của khách hàng đến chất lượng dịch vụ: Trường hợp của các ngân hàng Ira cho thấy sự hài lòng của khách hàng gồm 5 yếu tố: Đảm bảo, độ tin cậy, tính hữu hình, khả năng đáp ứng và sự đồng cảm [11]. Nghiên cứu của $J J$ Navaratnaseelan và $P$. Elangkumaran (2014) về Tác động của chất lượng phục vụ đối với khách hàng cá nhân: Một nghiên cứu về khách hàng của ngân hàng thương mại Ceylon PLC Trincomalee, kết quả nghiên cứu cho thẩy có 5 nhân tố ảnh hưởng đến chất lượng phục vụ đối với khách hàng cá nhân gồm: Tính hữu hình, độ tin cậy, phản hồi, đảm bảo và sự thông cảm [12].

Một số nghiên cứu trong nước: Nghiên cứu của Võ Thanh Hải và cộng sự (2017) về Sự hài lòng của khách hàng về chất lượng dịch vụ tại Ngân hàng Thương mại cổ phần Sài Gòn - Chi nhánh Đà Nẵng, kết quả nghiên cứu cho thấy có 3 yếu tố tác động đến mức độ hài lòng của khách hàng: Sự cảm thông, sự nổi trội, sự đáp ứng [13]; Nghiên cứu của Trần Thị Thanh Thuý (2018) về Chất lượng dịch vụ ngân hàng của các Ngân hàng thương mại Việt Nam, kết quả nghiên cứu cho thấy có 4 thành phần: Tin cậy, phương tiện hữu hình, đồng cảm, đáp ứng ảnh hưởng đến chất lượng dịch vụ ngân hàng [14]; Nghiên cứu của Hà Văn Dũng (2018) về Ẩnh hưởng của chất lượng dịch vụ đến sự hài lòng khách hàng cá nhân tại các ngân hàng thương mại, kết quả nghiên cứu cho thấy sự hài lòng của khách hàng cá nhân về chất lượng dịch vụ tại các ngân 
hàng thương mại gồm 5 yếu tố: Sự tin cậy, sự cảm thông, khả năng đáp ứng, phương tiện hữu hình và sự đảm bảo [15]. Nghiên cứu của Phạm Xuân Thành (2018) về Các yếu tố ảnh hưởng đến mức độ hài lòng của khách hàng cá nhân về chất lượng dịch vụ ngân hàng Vietinbank chi nhánh Đồng Tháp, Kết quả nghiên cứu cho thấy có 4 yếu tố: Tin cậy, cảm thông, hữu hình, thông tin sản phẩm; trong số những yếu tố này, "Tin cậy" là yếu tố quyết định quan trọng nhất đến sự hài lòng của khách hàng cá nhân về chất lượng dịch vụ ngân hàng [16].

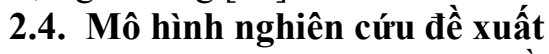

Thông qua quá trình nghiên cứu về các lý thuyết và mô hình nghiên cứu đã được thực hiện trước đây, nhóm nghiên cứu quyết định đề xuất mô hình nghiên cứu chính thức như sau:

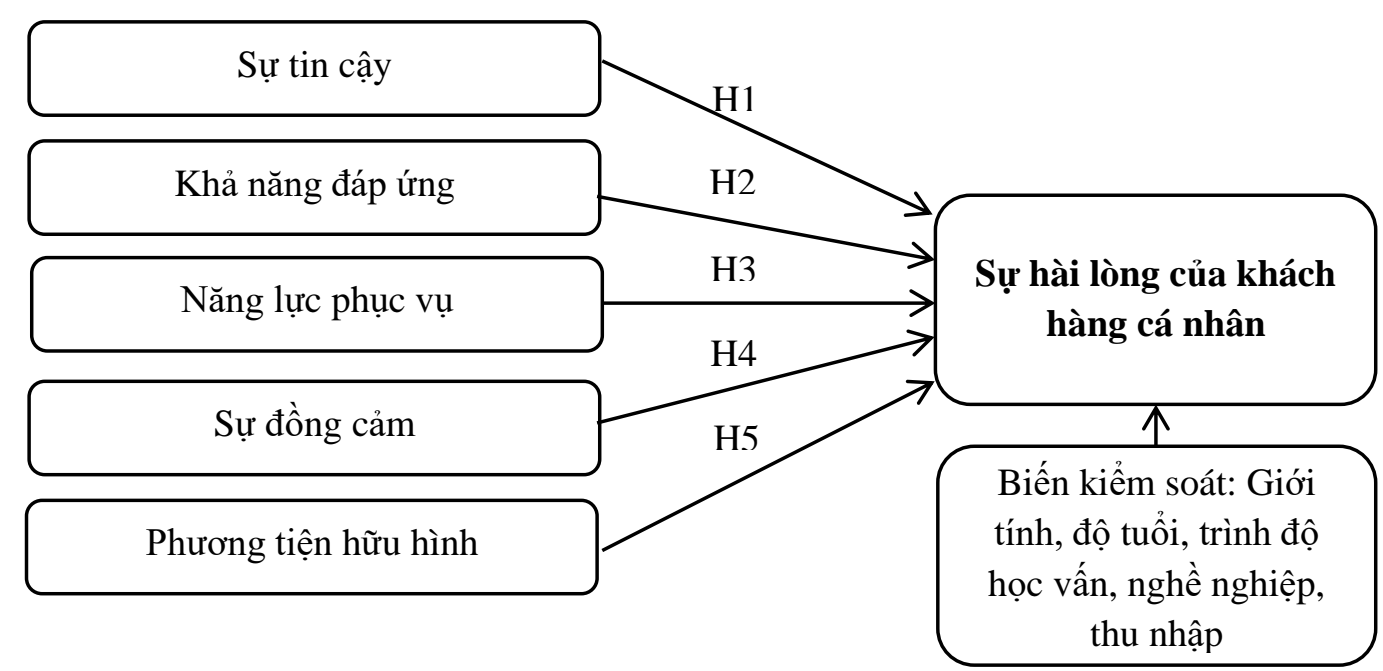

Hình 1: Mô hình các yếu tố ảnh hưởng đến sự hài lòng của khách hàng cá nhân đối với chất lượng dịch vụ tại BIDV - CNBP

Nguồn: Đề xuất của nhóm tác giả Trong đó: Yếu tố phụ thuộc là sự hài lòng của khách hàng cá nhân và các yếu tố độc lập là: (1) Sự tin cậy; (2) Khả năng đáp ứng; (3) Năng lực phục vụ; (4) Sự cảm thông; (5) Phương tiện hữu hình.

Các giả thuyết nghiên cứu:

- Sự tin cậy: Nói lên khả năng cung ứng dịch vụ chính xác, đúng giờ và uy tín. Điều này đòi hỏi sự nhất quán trong việc thực hiện dịch vụ và tôn trọng các cam kết cũng như giữ lời hứa với khách hàng. Theo đó ta có giả thuyết H1: Sự tin cậy ảnh hưởng tích cực đến sự hài lòng của khách hàng [13], [14], [16],[17].

- Khả năng đáp ứng: Thể hiện khả năng của Ngân hàng trong việc cung cấp kịp thời sản phẩm dịch vụ cũng như đáp ứng các yêu cầu về dịch vụ của khách hàng, khách hàng không phải mất nhiều thời gian chờ đợi. Từ đó, để nâng cao chất lượng dịch vụ, đội ngũ cán bộ nhân viên phải luôn nâng cao ý thức sẵn sàng trong công tác phục vụ và đáp ứng nhu cầu khách hàng kịp thời, nhanh chóng. Theo đó ta có giả thuyết $\mathrm{H} 2$ : Khả năng đáp ứng ảnh hưởng tích cực đến sự hài lòng của khách hàng [13], [14], [16], [17].

- Năng lực phục vụ: Thể hiện năng lực trình độ của đội ngũ cán bộ nhân viên và uy tín của Ngân hàng. Thể hiện thồng qua việc nhân viên có nắm vững kiến thức về sản phẩm dịch vụ, các kỹ năng giao tiếp và làm việc hiệu quả, giải quyết công việc nhanh chóng, ít mắc các sai sót trong quá trình tác nghiệp hay không... hơn nữa thái độ của nhân viên có ân cần, lịch sự, trân trọng khách hàng trong suốt quá trình phục vụ để tạo cảm giác thoải mái và hài lòng cho khách hàng hay không. Về góc độ Ngân hàng, Năng lực phục vụ thể hiện qua việc luôn xem khách hàng là trọng tâm, nâng cao tinh thần trách nhiệm trong công tác phục vụ khách hàng, làm cho khách hàng cảm thấy yên tâm và tín nhiệm Ngân hàng. Theo đó ta có giả thuyết H3: Năng lực phục vụ ảnh hưởng tích cực đến sự hài lòng của khách hàng [13], [14].

- Sự đồng cảm: Sự cảm thông chính là sự quan tâm, chăm sóc khách hàng ân cần, sự đối xử chu đáo tốt nhất có thể giúp cho khách hàng cảm thấy mình là "thượng khách" của Ngân hàng và luôn được đón tiếp nồng hậu mọi lúc, mọi nơi. Yếu tố con người là phần cốt lõi tạo nên sự thành công này và sự quan tâm 
của Ngân hàng đối với khách hàng càng nhiều thì sự cảm thông sẽ càng tăng. Theo đó ta có giả thuyết H4: Sự đồng cảm ảnh hưởng tích cực đến sự hài lòng của khách hàng [13], [14], [16],[17].

- Phương tiện hữu hình: Sự hữu hình chính là hình ảnh bên ngoài của cơ sở vật chất, thiết bị, máy móc, phong thái của đội ngũ nhân viên, tài liệu, sách hướng dẫn và hệ thống thông tin liên lạc của ngân hàng. Nói một cách tổng quát: Tất cả những gì mà khách hàng nhìn thấy trực tiếp được bằng mắt và các giác quan thì đều có thể tác động đến yếu tố này. Theo đó ta có giả thuyết H5: Phương tiện hữu hình ảnh hưởng tích cực đến sự hài lòng của khách hàng [13], [14], [16],[17].

\section{PHƯƠNG PHÁP NGHIÊN CÚU}

Trong nghiên cứu này, nhóm tác giả đã vận dụng kết hợp 2 phương pháp: Nghiên cứu định tính và nghiên cứu định lượng.

Trong nghiên cứu định tính, nhóm tác giả đã tiến hành theo các bước sau:

- Tìm hiểu các cơ sở lý thuyết, các công trình nghiên cứu trước đây có liên quan đến chủ đề nghiên cứu để đề xuất mô hình và xây dựng bảng khảo sát sơ bộ.

- Nhóm tác giả đã tiến hành phỏng vấn trực tiếp, trao đổi thảo luận với 31 người (bao gồm 25 khách hàng cá nhân sử dụng dịch vụ tại BIDV - CNBP và 6 chuyên gia). Tất cả ý kiến của 31 người được tổng hợp, điều chỉnh để đưa ra bảng câu hỏi chính thức.

- Nhóm tác giả đã xây dựng hoàn chỉnh bảng khảo sát nhằm phục vụ cho bước nghiên cứu định lượng. Bảng câu hỏi chính thức với 24 biến quan sát (bảng 1), trong đó bao gồm 05 yếu tố độc lập (với 21 biển quan sát) được sắp xếp theo thứ tự: Sự tin cậy; Khả năng đáp ứng; Năng lực phục vụ; Sự đồng cảm; Phương tiện hữu hình và 01 yếu tố phụ thuộc là Sự hài lòng của khách hàng (với 3 biến quan sát).

Bảng 1: Thang đo các thành phần ảnh hưởng đến sự hài lòng của khách hàng cá nhân đối với chất lượng dịch vụ tại BIDV - CNBP

\begin{tabular}{|c|c|c|c|}
\hline TT & Mã hóa & Biến quan sát & Nguồn \\
\hline 1 & STC1 & Ngân hàng luôn đảm bảo thực hiện dịch vụ chính xác & \multirow{4}{*}{$\begin{array}{l}\text { Đặng Thị Mỹ } \\
\text { Xuân (2018), } \\
\text { NCĐT }\end{array}$} \\
\hline 2 & STC2 & Ngân hàng luôn thực hiện đúng cam kết với khách hàng & \\
\hline 3 & STC3 & Ngân hàng luôn đảm bảo phối hợp với khách hàng xử lý trở ngại & \\
\hline 4 & STC4 & Ngân hàng bảo mật thông tin giao dịch cho khách hàng & \\
\hline 5 & KNDU1 & Ngân hàng sã̃n sàng đáp ứng các yêu cầu của khách hàng & \multirow{3}{*}{$\begin{array}{c}\text { Đặng Thị Mỹ } \\
\text { Xuân (2018), } \\
\text { NCĐT }\end{array}$} \\
\hline 6 & KNDU2 & $\begin{array}{l}\text { Tất cả giao dịch của khách hàng được Ngân hàng cập nhật nhanh } \\
\text { chóng và chính xác }\end{array}$ & \\
\hline 7 & KNDU3 & Thời gian xử lý giao dịch của Ngân hàng nhanh chóng và chính xác & \\
\hline 8 & NLPV1 & Cách cư xử của nhân viên tạo niềm tin cho khách hàng & $\begin{array}{l}\text { Đặng Thị Mỹ } \\
\text { Xuân (2018), } \\
\text { NCĐT }\end{array}$ \\
\hline 9 & NLPV2 & Thái độ phục vụ của nhân viên luôn vui vẻ, niềm nở & \multirow{2}{*}{$\begin{array}{l}\text { Trần Thị Thanh } \\
\text { Thuý (2018) }\end{array}$} \\
\hline 10 & NLPV3 & $\begin{array}{l}\text { Nhân tiên tư vấn và trả lời rõ ràng, thoả đáng những vướng mắc của } \\
\text { khách hàng }\end{array}$ & \\
\hline 11 & NLPV4 & Khách hàng được nhân viên thông báo khi xử lý giao dịch & $\begin{array}{l}\text { Đặng Thị Mỹ } \\
\text { Xuân (2018) }\end{array}$ \\
\hline 12 & NLPV5 & $\begin{array}{l}\text { Nhân viên ngân hàng có đủ hiểu biết để trả lời câu hỏi của khách } \\
\text { hàng }\end{array}$ & \multirow{4}{*}{$\begin{array}{l}\text { Trần Thị Thanh } \\
\text { Thuý (2018) }\end{array}$} \\
\hline 13 & SDC1 & Thời gian xử lý các yêu cầu của khách hàng là hợp lý & \\
\hline 14 & SDC2 & Thời gian làm việc của Ngân hàng phù hợp và thuận tiện & \\
\hline 15 & SDC3 & Ngân hàng lấy lợi ích của khách hàng là điều tâm niệm & \\
\hline 16 & PTHH1 & Trang thiết bị của Ngân hàng hiện đại & \multirow{3}{*}{$\begin{array}{l}\text { Đặng Thị Mỹ } \\
\text { Xuân (2018) }\end{array}$} \\
\hline 17 & PTHH2 & Cơ sở vật chất của Ngân hàng khang trang, tiện nghi & \\
\hline 18 & PTHH3 & Giao diện website rõ ràng, thu hút & \\
\hline
\end{tabular}




\begin{tabular}{|c|c|c|c|}
\hline 19 & PTHH4 & $\begin{array}{l}\text { Tờ rơi, poster quảng cáo của Ngân hàng trình bày đẹp, rõ ràng, dễ } \\
\text { hiểu }\end{array}$ & \\
\hline 20 & PTHH5 & $\begin{array}{l}\text { Ngân hàng sắp xếp các quầy giao dịch, các bảng biểu và kệ tài liệu } \\
\text { rất khoa học và tiện lợi cho khách hàng }\end{array}$ & \\
\hline 21 & PTHH6 & Trang phục của nhân viên tươm tất và đồng bộ & \\
\hline 22 & SHL1 & Khách hàng hài lòng về chất lượng dịch vụ của BIDV - CNBP & \multirow{3}{*}{$\begin{array}{l}\text { Đặng Thị My } \\
\text { Xuân (2018) }\end{array}$} \\
\hline 23 & SHL2 & Khách hàng tiếp tục sử dụng dịch vụ của BIDV - CNBP & \\
\hline 24 & SHL3 & $\begin{array}{l}\text { Khách hàng sẽ giới thiệu dịch vụ của BIDV - CNBP cho người thân, } \\
\text { bạn bè,... }\end{array}$ & \\
\hline
\end{tabular}

Nguồn: Tổng hợp của nhóm tác giả từ quá trình nghiên cứu định tính Nghiên cứu định lượng được thực hiện thông qua kỹ thuật phỏng vấn trực tiếp bằng bảng câu hỏi khảo sát được đo lường dựa trên thang đo Likert gồm 5 điểm: Từ (1) Hoàn toàn không hài lòng, đến (5) Hoàn toàn hài lòng. Sau khi thu thập, dữ liệu được xử lý bằng phần mềm SPSS phiên bản 22.0. Phương pháp chọn mẫu thuận tiện được sử dụng trong nghiên cứu, mẫu khảo sát được nhóm tác giả tiến hành bằng cách khảo sát trực tiếp các khách hàng đến giao dịch tại BIDV - CNBP thông qua bảng câu hỏi khảo sát và nhóm tác giả đã quyết định chọn kích thước mẫu là 300 phiếu. Sau khi phát ra 300 phiếu khảo sát tại các phòng giao dịch tại BIDV - CNBP, nhóm tác giả thu về được 275 phiếu hợp lệ.

\section{KẾT QUẢ NGHIÊN CÚ̉ VÀ THẢO LUẬN}

\subsection{Kết quả kiểm định độ tin cậy của các thang đo}

Tóm tắt mô tả đặc điểm khảo sát. Kết quả thực hiện phân tích thống kê mô tả ở bảng 2 cho thấy:

- Về giới tính: Nam có 136 mẫu (49.5\%) và nữ có 139 mẫu (50.5\%).

- Về độ tuổi: Từ 18 - 30 có 55 mẫu (20\%), từ 31 - 40 có 67 mẫu (24.4\%), từ 41 - 50 có 71 mẫu $(25.8 \%)$ và trên 50 có 82 mẫu (29.8\%).

- Về học vấn: Trung cấp có 69 mẫu (25.1\%), cao đẳng, đại học có 74 mẫu (26.9\%), trên đại học có 65 mẫu (23.6\%) và trình độ khác có 67 mẫu $(24.4 \%)$.

- Về nghề nghiệp: Làm nông có 71 mẫu (25.8\%), buôn bán/kinh doanh có 69 mẫu (25.1\%), cán bộ/nhân viên có 69 mẫu (25.1\%) và nghề nghiệp khác có 66 mẫu (24.0\%).

- Về thu nhập: Dưới 5 triệu có 72 mẫu (26.2\%), từ 5 - dưới 10 triệu có 69 mẫu (25.1\%), từ 10 - dưới 20 triệu có 73 mẫu (26.5\%) và từ 20 triệu trở lên có 61 mẫu (22.2\%).

Bảng 2: Thông tin về mẫu khảo sát

\begin{tabular}{|c|c|c|c|}
\hline \multirow{2}{*}{ Biến nhân khẩu học } & \multirow{2}{*}{ Phân loại } & \multicolumn{2}{|c|}{ Mẫu nghiên cứu hợp lệ } \\
\hline & & Tấn số (mẫu) & $\%$ \\
\hline \multirow{2}{*}{ Giới tính } & Nam & 136 & 49.5 \\
\hline & Nữ & 139 & 50.5 \\
\hline \multicolumn{2}{|l|}{ Tổng } & 275 & 100 \\
\hline \multirow{4}{*}{ Độ tuổi } & Từ $18-30$ & 55 & 20.0 \\
\hline & Từ $31-40$ & 67 & 24.4 \\
\hline & Từ $41-50$ & 71 & 25.8 \\
\hline & Trên 50 & 82 & 29.8 \\
\hline \multicolumn{2}{|l|}{ Tổng } & 275 & 100 \\
\hline \multirow{4}{*}{ Học vấn } & Trung cấp & 69 & 25.1 \\
\hline & Cao đẳng, Đại học & 74 & 26.9 \\
\hline & Trên Đại học & 65 & 23.6 \\
\hline & Khác & 67 & 24.4 \\
\hline \multicolumn{2}{|l|}{ Tổng } & 275 & 100 \\
\hline \multirow{4}{*}{ Nghề nghiệp } & Làm nông & 71 & 25.8 \\
\hline & Buôn bán/ kinh doanh & 69 & 25.1 \\
\hline & Cán bộ/nhân viên & 69 & 25.1 \\
\hline & Khác & 66 & 24.0 \\
\hline
\end{tabular}




\begin{tabular}{|l|l|c|c|}
\hline \multirow{2}{*}{ Biến nhân khẩu học } & \multirow{2}{*}{ Phân loại } & \multicolumn{2}{c|}{ Mẫu nghiên cứu hợp lệ } \\
\cline { 3 - 4 } & & Tấn số (mẫu) & $\mathbf{\%}$ \\
\hline Tổng & Dưới 5 triệu & $\mathbf{2 7 5}$ & $\mathbf{1 0 0}$ \\
\hline \multirow{3}{*}{ Thu nhập } & Từ 5- dưới 10 triệu & 72 & 26.2 \\
\cline { 2 - 4 } & Từ 10- dưới 20 triệu & 69 & 25.1 \\
\cline { 2 - 4 } & Từ 20 triệu trở lên & 73 & 26.5 \\
\hline \multicolumn{2}{|l|}{ Tổng } & 61 & 22.2 \\
\hline
\end{tabular}

Nguồn: Kết quả kiểm định độ tin cậy của các thang đo của nhóm tác giả Kết quả phân tích độ tin cậy của thang đo của các yếu tố tố độc lập và phụ thuộc được trình bày trong bảng 3. Số liệu khảo sát chính thức ban đầu gồm 24 biến quan sát cho 5 yếu tố độc lập (21 biến quan sát) và 1 yếu tố phụ thuộc (3 biến quan sát), sau khi thực hiện phân tích độ tin cậy cho tất cả các thang đo cho thấy có 22 biến quan sát đủ độ tin cậy để thực hiện các bước phân tích tiếp theo. Chỉ riêng 2 biến quan sát PTHH3 $=0.182$ và biến PTHH4 $=0.075$ nhỏ hơn 0.3 không đủ độ tin cậy nên bị loại khỏi thang đo, bị loại ra khỏi mô hình nghiên cứu vì không thỏa mãn điều kiện hệ số tương quan biến - tổng > $=0.3$ ).

Bảng 3: Kết quả kiểm định độ tin cậy của các thang đo

\begin{tabular}{|c|c|c|c|c|}
\hline $\begin{array}{l}\text { Biến quan } \\
\text { sát }\end{array}$ & $\begin{array}{l}\text { Trung bình thang đo } \\
\text { nếu loại biến }\end{array}$ & $\begin{array}{c}\text { Phương sai thang đo nếu } \\
\text { loại biến }\end{array}$ & $\begin{array}{l}\text { Tương quan biến - } \\
\text { tồng }\end{array}$ & $\begin{array}{l}\text { Hệ số Cronbach's } \\
\text { Alpha nếu loại biến }\end{array}$ \\
\hline
\end{tabular}

Sự tin cậy - STC: Cronbach's Alpha $=0.891$

\begin{tabular}{|c|c|c|c|c|}
\hline STC1 & 10.98 & 9.189 & 0.760 & 0.859 \\
\hline STC2 & 10.95 & 9.147 & 0.788 & 0.849 \\
\hline STC3 & 10.87 & 9.177 & 0.744 & 0.866 \\
\hline STC4 & 10.69 & 9.309 & 0.747 & 0.864 \\
\hline
\end{tabular}

Khả năng đáp ứng - KNDU: Cronbach's Alpha $=0.868$

\begin{tabular}{|c|c|c|c|c|}
\hline KNDU1 & 7.28 & 4.865 & 0.700 & 0.864 \\
\hline KNDU2 & 6.89 & 4.889 & 0.763 & 0.801 \\
\hline KNDU3 & 6.91 & 5.122 & 0.791 & 0.781 \\
\hline
\end{tabular}

Năng lực phục vụ - NLPV: Cronbach 's Alpha $=0.839$

\begin{tabular}{|c|c|c|c|c|}
\hline NLPV1 & 12.55 & 7.154 & 0.792 & 0.770 \\
\hline NLPV2 & 12.49 & 7.047 & 0.681 & 0.795 \\
\hline NLPV3 & 12.46 & 7.169 & 0.655 & 0.802 \\
\hline NLPV4 & 12.38 & 7.470 & 0.535 & 0.838 \\
\hline
\end{tabular}

Sự đồng cảm - SDC: Cronbach 's Alpha $=0.890$

\begin{tabular}{|c|c|c|c|c|}
\hline & & & \\
\hline SDC1 & 6.33 & 2.186 & 0.819 & 0.814 \\
\hline SDC2 & 6.56 & 2.452 & 0.767 & 0.859 \\
\hline SDC3 & 6.48 & 2.557 & 0.774 & 0.854 \\
\hline \multicolumn{5}{|c|}{ Phương tiện hữu hình - PTHH: Cronbach 's Alpha $=0.839$} \\
\hline PTHH1 & 11.05 & 5.139 & 0.678 & 0.794 \\
\hline PTHH2 & 10.97 & 4.853 & 0.666 & 0.799 \\
\hline PTHH5 & 11.05 & 5.125 & 0.667 & 0.798 \\
\hline PTHH6 & 10.62 & 4.850 & 0.677 & 0.794 \\
\hline \multicolumn{5}{|c|}{ Sự hài lòng của khách hàng - SHL: Cronbach 's Alpha = 0.834} \\
\hline SHL1 & 6.36 & 2.444 & 0.683 & 0.785 \\
\hline SHL2 & 6.67 & 2.330 & 0.741 & 0.723 \\
\hline SHL3 & 6.59 & 2.790 & 0.670 & 0.798 \\
\hline
\end{tabular}

Nguồn: Kết quả kiểm định độ tin cậy của các thang đo của nhóm tác giả 


\subsection{Kết quả phân tích nhân tố khám phá}

Kết quả thực hiện phân tích nhân tố khám phá đối với những biến quan sát của các yếu tố độc lập lần thứ nhất cho thấy trong số 19 biến quan sát thì giá trị của biến quan sát NLPV4 "Khách hàng được nhân viên thông báo khi xử lý giao dịch" được tải lên ở cả 2 nhân tố 1 và 2 , vi phạm tính phân biệt trong ma trận xoay với hệ số tải lần lượt là 0.372 và 0.621 , mức chênh lệch hệ số tải là $0.249<0.3$ nên biến quan sát này bị loại khỏi thang đo.

Bảng 4: Kết quả phân tích nhân tố khám phá đối với các yếu tố độc lập

\begin{tabular}{|c|c|c|c|c|c|}
\hline \multirow{2}{*}{ Ký hiệu biến quan sát } & \multicolumn{5}{|c|}{ Nhân tố } \\
\hline & 1 & 2 & 3 & 4 & 5 \\
\hline STC1 & 0.872 & & & & \\
\hline STC2 & 0.860 & & & & \\
\hline STC3 & 0.833 & & & & \\
\hline STC4 & 0.826 & & & & \\
\hline NLPV1 & & 0.851 & & & \\
\hline NLPV2 & & 0.838 & & & \\
\hline NLPV3 & & 0.809 & & & \\
\hline NLPV5 & & 0.721 & & & \\
\hline PTHH5 & & & 0.820 & & \\
\hline PTHH6 & & & 0.820 & & \\
\hline PTHH2 & & & 0.814 & & \\
\hline PTHH1 & & & 0.812 & & \\
\hline SDC1 & & & & 0.923 & \\
\hline SDC2 & & & & 0.863 & \\
\hline SDC3 & & & & 0.855 & \\
\hline KNDU2 & & & & & 0.883 \\
\hline KNDU3 & & & & & 0.871 \\
\hline KNDU1 & & & & & 0.845 \\
\hline Giá trị Eigenvalues & 4.833 & 2.930 & 2.042 & 1.922 & 1.664 \\
\hline Phương sai trích & & & & & $74.392 \%$ \\
\hline Hệ số KMO & & & & & 0.793 \\
\hline
\end{tabular}

Nguồn: Kết quả phân tích nhân tố khám phá của nhóm tác giả Kết quả thực hiện phân tích nhân tố khám phá lần thứ 2 cho 18 biến quan sát của còn lại của các yếu tố độc lập ở bảng 3 cho thấy: Sau khi phân tích nhân tố khám phá EFA thì mô hình khảo sát không có sự thay đổi.

- Hệ số $0.5<\mathrm{KMO}=0.793<1$ (Bảng 3) ở mức ý nghĩa Sig (kiểm định Bartlett) $=0.000<0.5$, điều này cho thấy việc phân tích nhân tố khám phá của các nhân tố hoàn toàn phù hợp, đáng tin cậy và có ý nghĩa. Điều này cho thấy các biến quan sát có tương quan với nhau trong tổng thể.

- Kết quả phân tích (Bảng 3) cũng cho thấy tất cả các nhân tố đều có giá trị Eigenvalues $>1$, phương sai trích bằng $74.392 \%>50 \%$ là đạt yêu cầu. Với phương pháp rút trích phân tích thành phần chính và phép xoay Varimax, có 5 nhân tố được rút trích ra từ 18 biến quan sát, điều này cho thấy 5 nhân tố rút trích ra đã giải thích được $74.392 \%$ sự thay đổi của biến phụ thuộc trong tổng thể quan sát/dữ liệu.

- Ngoài ra, nhóm tác giả cũng tiến hành phân tích nhân tố khám phá EFA cho 3 biến quan sát của yếu tố phụ thuộc được gom thành 1 nhân tố, với hệ số mức độ phù hợp của mô hình phân tích nhân tố KMO = $0.715>0.5$ nên phân tích nhân tố hoàn toàn phù hợp, đáng tin cậy và Sig. (Bartletts Test of Sphericity) $=$ $0.000<0.05$ chứng tỏ các biến quan sát có tương quan với nhau xét trên phạm vi tổng thể.

\subsection{Kết quả phân tích hồi qui}

Kết quả chạy mô hình hồi quy tuyến tính đa biến, trong đó sự hài lòng của khách hàng cá nhân là yếu tố phụ thuộc; còn lại 5 yếu tố độc lập (sự tin cậy, khả năng đáp ứng, năng lực phục vụ, sự đồng cảm và phương tiện hữu hình) cho thấy: hệ số tương quan $R(0.775)$ đã được chứng minh là hàm không giảm theo số yếu tố độc lập được đưa vào mô hình ( 5 yếu tố). $\mathrm{R}^{2}=0.569$ đã thể hiện thực tế của mô hình. Hệ số $\mathrm{R} 2$ hiệu chỉnh từ $\mathrm{R} 2$ được sử dụng để phản ánh sát hơn mức độ phù hợp của mô hình hồi quy đa biến $(0.561)$, vì nó 


\section{CÁC YẾU TỐ ẢNH HƯỞNG ĐẾN SỰ HÀI LÒNG CỦA KHÁCH HÀNG CÁ NHÂN ĐỐI VỚI CHẤT LƯợNG DỊCH VỤ TẠI NGÂN HÀNG TMCP ĐẦU TƯ VÀ PHÁT TRIẾN VIẸTT NAM - CHI NHÁNH BÌNH PHƯỚC}

không phụ thuộc vào độ lệch phóng đại của R2. Như vậy, với R2 điều chỉnh là 0.561 cho thấy sự tương thích của mô hình với biến quan sát và yếu tố phụ thuộc sự hài lòng của khách hàng cá nhân gần như hoàn toàn được giải thích bởi 5 yếu tố độc lập trong mô hình, ngoài ra kết quả phân tích hồi quy cũng thấy giá trị của Sig. $=0.00<0.05$, ta có thể kết luận phương trình hồi quy được đưa ra là phù hợp với cả mẫu và tổng thể nghiên cứu. Từ bảng tóm tắt kết quả chạy hồi quy cho thấy có 5 yếu tố tác động được đưa vào mô hình phân tích hồi quy, các biến đều có quan hệ tuyến tính với yếu tố sự hài lòng của khách hàng cá nhân do các hệ số Sig đều nhỏ hơn $5 \%$.

Bảng 5: Kết quả phân tích hồi qui

\begin{tabular}{|c|c|c|c|c|c|c|c|}
\hline \multirow{2}{*}{ Mô hình } & \multicolumn{2}{|c|}{ Hệ số chưa chuẩn hóa } & \multirow{2}{*}{$\begin{array}{c}\text { Hệ số chuẩn hóa } \\
\text { Beta }\end{array}$} & \multirow{2}{*}{$\mathbf{t}$} & \multirow{2}{*}{ Sig } & \multicolumn{2}{|c|}{ Thống kê đa cộng tuyến } \\
\hline & B & Std. Error & & & & Tolerance & VIF \\
\hline Hằng số & -0.531 & 0.232 & & -2.293 & 0.023 & & \\
\hline STC & 0.270 & 0.034 & 0.351 & 8.031 & 0.000 & 0.838 & 1.194 \\
\hline KNDU & 0.201 & 0.031 & 0.284 & 6.563 & 0.000 & 0.857 & 1.167 \\
\hline 1 NLPV & 0.265 & 0.048 & 0.237 & 5.458 & 0.000 & 0.850 & 1.176 \\
\hline SDC & 0.184 & 0.044 & 0.182 & 4.206 & 0.000 & 0.853 & 1.172 \\
\hline PTHH & 0.194 & 0.043 & 0.184 & 4.498 & 0.000 & 0.853 & 1.049 \\
\hline \multicolumn{2}{|c|}{ Hệ số Sig.F của mô hình } & & & & & & 0.000 \\
\hline \multicolumn{2}{|l|}{ Hệ sô R2 } & & & & & & 0.569 \\
\hline \multicolumn{2}{|c|}{ Hệ số R2 hiệu chỉnh } & & & & & & 0.561 \\
\hline \multicolumn{2}{|c|}{ Hệ số Durbin - Watson } & & & & & & 2.284 \\
\hline
\end{tabular}

Nguồn: Kết quả phân tích hồi qui của nhóm tác giả

Kiểm định hiện tượng tự tương giữa các phần dư bằng hệ số Durbin-Watson, không có tương quan giữa các phần dư thì $1<$ Durbin-Watson $<3$, theo Hoàng Trọng và Chu Nguyễn Mộng Ngọc (2008). Kết quả phân tích có đại lượng thống kê Durbin-Watson = $2.284(1<2.284<3)$ cho thấy không có sự tương quan giữa các phần dư. Điều này có ý nghĩa là mô hình hồi quy không vi phạm giả định về tính độc lập của sai số. Phương trình hồi qui ước lượng các yếu tố ảnh hưởng đến mức độ hài lòng của khách hàng cá nhânđối với chất lượng dịch vụ tại BIDV - CNBP được thiết lập như sau:

Sự hài lòng của khách hàng cá nhân $=0.351 *$ Sự tin cậy $+0.284 *$ Khả năng đáp ứng $+0.237 *$ Năng lực phục vụ $+0.182 *$ Sự đồng cảm $+0.184 *$ Phương tiện hữu hình.

Dựa vào kết quả phân tích kiểm định mô hình hồi quy cho thấy: Tất cả 5 yếu tố độc lập trong mô hình đề xuất đều có sự tương quan cùng chiều với yếu tố phụ thuộc, do đó có thể kết luận: các giả thuyết $\mathrm{H} 1 ; \mathrm{H} 2$; H3; H4; H5 đều được chấp nhận. Trong đó mức độ ảnh hưởng của từng yếu tố đối với sự hài lòng của khách hàng cá nhân như sau: Yếu tố ảnh hưởng mạnh nhất là Sự tin cậy với hệ số beta chuẩn hoá bằng 0.351 ; ảnh hưởng thứ 2 là yếu tố Khả năng đáp ứng với hệ số beta chuẩn hoá bằng 0.284 ; Thứ 3 là yếu tố Năng lực phục vụ với hệ số beta chuẩn hoá bằng 0.237 ; Thứ 4 là yếu tố Phương tiện hữu hình với hệ số beta chuẩn hoá bằng 0.184 ; Cuối cùng là yếu tố Sự đồng cảm với hệ số beta chuẩn hoá bằng 0.182 .

Kết quả nghiên cứu của đề tài sau phân tích hồi quy đa biến và kiểm định các giả thuyết nghiên cứu cho thấy:

- Kết quả của mô hình nghiên cứu này đã được tác giả kiểm định về mặt giá trị thông qua việc tiến hành khảo sát và thực hiện các bước phân tích kiểm định đã trình bày trong các phần nêu trên.

- Kết quả của mô hình nghiên cứu này phù hợp với tập dữ liệu khảo sát, 5 yếu tố có ảnh hưởng đến sự hài lòng của khách hàng cá nhân đối với chất lượng dịch vụ tại BIDV - CNBP với mức độ ảnh hưởng theo thứ tự giảm dần lần lượt là: (1) Sự tin cậy; (2); Khả năng đáp ứng; (3) Năng lực phục vụ; (4) Phương tiện hữu hình; (5) Sự đồng cảm.

\section{THẢO LUẬN KẾT QUẢ NGHIÊN CÚU VÀ HÀM Ý QUẢN TR!}

\subsection{Thảo luận kết quả nghiên cứu}

Quá trình hoạt động kinh doanh trong lĩnh vực ngân hàng ngày nay luôn có sự cạnh tranh mạnh mẽ, do đó việc tìm hiểu và nghiên cứu về các yếu tố ảnh hưởng đến sự hài lòng của khách hàng cá nhân đối với chất lượng dịch vụ tại BIDV - CNBP là việc làm rất cần thiết. Kết quả nghiên cứu cho thấy: Sự hài lòng của 
khách hàng cá nhân đối với chất lượng dịch vụ tại BIDV - CNBP chịu ảnh hưởng bởi 5 yếu tố: (1) Sự tin cậy; (2); Khả năng đáp ứng; (3) Năng lực phục vụ; (4) Phương tiện hữu hình; (5) Sự đồng cảm.

Kết quả nghiên cứu cũng giúp tác giả trả lời được các câu hỏi đề ra trong phần mục tiêu nghiên cứu: (1) Các yếu tố nào ảnh hưởng đến sự hài lòng của khách hàng cá nhân về chất lượng dịch vụ của BIDV CNBP? (2) Mức độ ảnh hưởng của các yếu tố đến sự hài lòng của khách hàng cá nhân về chất lượng dịch vụ của BIDV - CNBP như thế nào? (3) Hàm ý quản trị nào nhằm nâng cao sự hài lòng của khách hàng cá nhân về chất lượng dịch vụ của BIDV - CNBP?

Ngoài ra, kết quả nghiên cứu cũng mang lại những đóng góp nhất định về mặt lý thuyết và thực tiễn:

- Về mặt lý thuyết: Kết quả nghiên cứu đã chứng minh được mô hình nghiên cứu phù hợp với một số nghiên cứu về sự hài lòng của khách hàng cá nhân đã thực hiện trước đây: Snehalkumar H Mistry (2013); Võ Thanh Hải và cộng sự (2017); Trần Thị Thanh Thuý (2018); Hà Văn Dũng (2018); Phạm Xuân Thành (2018); Anas Salman Alabboodi (2018).

- Về mặt thực tiễn: Kết quả nghiên cứu của tác giả sẽ góp phần giúp cho Ban lãnh đạo BIDV - CNBP có những đánh giá khách quan và toàn diện hơn về chất lượng dịch vụ tại BIDV - CNBP, từ đó có những cải tiến phù hợp để nâng cao chất lượng dịch vụ và sự hài lòng của khách hàng cá nhân để cạnh tranh với các ngân hàng bạn trên địa bàn.

\subsection{Hàm ý quản trị}

Đối với yếu tố sụ tin cậy: BIDV - CNBP cần thường xuyên rà soát và đánh giá lại những cam kết của Ngân hàng đối với khách hàng để kịp thời có những điều chỉnh phù hợp nhằm đảm bảo được tất cả các quyền lợi của khách hàng theo đúng những cam kết đã thông báo và phù hợp với tình hình hiện tại. Trong quá trình sử dụng dịch vụ, khi khách hàng gặp bất kỳ trở ngại nào các nhân viên của Ngân hàng phải cam kết luôn hỗ trợ, giải đáp kịp thời các vướng mắc cho các khách hàng. Ngân hàng cần phải thực hiện tốt việc bảo mật tất cả những thông tin giao dịch của khách hàng, tuyệt đối không để những thông tin cá nhân của khách hàng bị rò rỉ ra bên ngoài.

Đối với yếu tố khả năng đáp úng: BIDV - CNBP cần thường xuyên khảo sát nhu cầu của khách hàng để bổ sung những sản phẩm/dịch vụ còn thiếu, chưa hoàn thiện, phát triển những sản phẩm mới đặc thù tạo sự khác biệt so với các Ngân hàng khác như gói: BIC - Bảo An; Xem xét và đánh giá về các loại biểu phí, lãi xuất, chiết khấu phù hợp với đặc thù của kinh tế - xã hội tỉnh Bình Phước nhằm thu hút khách hàng trong thời gian tới; Đa dạng hoá các sản phẩm dịch vụ về tiền gửi, tín dụng, chuyển tiền,... ngày càng hiện đại; Ngân hàng cần đơn giản hóa thủ tục, tự động hóa thao tác thực hiện để giảm thiểu thời gian giao dịch của khách hàng. Xây dựng quy trình xử lý nghiệp vụ nhất quán, thông suốt giữa các Phòng để rút ngắn thời gian chờ đợi của khách hàng.

Đối với yếu tố năng lục phục vụ: Xây dựng hoàn thiện đội ngũ nhân viên có tịnh thần trách nhiệm cao, luôn niềm nở với khách hàng, giúp đỡ nhiệt tình, biết chia sẻ và xem trọng tất cả các khách hàng sử dụng dịch vụ tại BIDV - CNBP; Cải thiện tốt hơn về chất lượng đường dây nóng hỗ trợ khách hàng thuận tiện liên lạc với $\mathrm{Ngân}$ hàng nhằm giải đáp các thắc mắc, khiếu nại phát sinh về các sản phẩm dịch vụ tại $\mathrm{BIDV}$ - CNBP; Các nhân viên tại BIDV - CNBP cần phải luôn thể hiện được sự niềm nở, tận tình hỗ trợ mọi thắc mắc của khách hàng để họ luôn có cảm giác an tâm, an toàn khi thực hiện các giao dịch với Ngân hàng; Bên cạnh đó, tiếp tục hoàn thiện công tác đào tạo và bồi dưỡng nghiệp vụ chuyên môn cho đội ngũ nhân viên nhằm trang bị đầy đủ các kỹ năng cần thiết để đáp ứng tốt các yêu cầu của khách hàng.

Đối với yếu tố phương tiện hũu hình: BIDV - CNBP cần tiếp tục tập trung xây dựng cơ sở dữ liệu đồng bộ với toàn hệ thống của BIDV Việt Nam, kịp thời cập nhật và bổ sung những thông tin mới về các gói sản phẩm dịch vụ mà Ngân hành mình đang cung cấp cho khách hàng cá nhân; Các ấn phẩm, tài liệu giới thiệu về các sản phẩm dịch vụ của Ngân hàng đang cung cấp cho khách hàng cá nhân cần phải thường xuyên được cập nhật và cải thiện về nội dung cũng như hình thức nhằm tạo thuận lợi cho khách hàng tham khảo để lựa chọn các sản phẩm dịch vụ mà khách hàng đang tìm kiếm.

Đối với yếu tố sự đồng cảm: Việc khách hàng chưa đánh giá cao yếu tố này thể hiện đúng với thực tế tại ngân hàng hiện nay. Thời gian xử lý các yêu cầu của khách hàng còn chậm, khách hàng phải chờ đợi lâu vẫn còn diễn ra. Do đó trong thời gian tới Ban lãnh đạo BIDV - CNBP cần chú ý có những biện pháp hữu hiệu hơn để giảm thời gian thực hiện các giao dịch với khách hàng như: Hoàn thiện các quy trình nghiệp vụ, mẫu biểu, hồ sơ chứng từ đơn giản mà vẫn đáp ứng được yêu cầu của công việc; $\mathrm{Ngân} \mathrm{hàng} \mathrm{lấy} \mathrm{lợi} \mathrm{ích}$ 


\section{CÁC YẾU TỐ ẢNH HƯỞNG ĐÊN SỰ HÀI LÒNG CỦA KHÁCH HÀNG CÁ NHÂN ĐỐI VỚI CHÂT LƯợNG DỊCH VỤ TẠI NGÂN HÀNG TMCP ĐẦU TƯ VÀ PHÁT TRIẾN VIẸTT NAM - CHI NHÁNH BİNH PHƯỚC}

của khách hàng là điều tâm niệm. Phục vụ khách hàng là sứ mệnh của Ngân hàng. Đối với các khách hàng thân thiết, BIDV - CNBP cần có những chương trình chăm sóc khách hàng vào các dịp lễ, tết, sinh nhật,... bằng những hành động cụ thể như nhắn tin, viết e-mail chúc mừng, tặng các món quà có giá trị, tặng voucher mua sắm, chăm sóc sức khoẻ,... nhằm gia tăng sự gắn kết, sự hài lòng của khách hàng đối với ngân hàng. Đối với khách hàng mới, BIDV - CNBP cần có những chương trình ưu đãi hấp dẫn như: giảm phí chuyển tiền khi giao dịch qua kênh Smartbanking, giảm phí mở thẻ ATM khi đăng ký thêm dịch vụ báo tin nhắn,...

\subsection{Hạn chế và hướng nghiên cứu tiếp theo}

Nhũng hạn chế của đề tài: Thông qua các bước nghiên cứu đã trình bày ở trên, đề tài nghiên cứu của nhóm tác giả đã có những đóng góp cụ thể về các yếu tổ ảnh hưởng đến sự hài lòng của khách hàng cá nhân tại BIDV - CNBP, tuy nhiên nghiên cứu này vẫn còn một số hạn chế như:

- Về chọn mẫu: Phương pháp khảo sát được thưc hiện bằng cách chọn mẫu thuận tiện nên tính đại diện vẫn còn thấp và khả năng bao quát vấn đề nghiên cứu còn chưa cao; Kích cỡ mẫu nghiên cứu còn chưa lớn so với số lượng khách hàng hiện tại của $\mathrm{BIDV}$ - CNBP, vì vậy cũng có những ảnh hưởng nhất định đến tính khách quan của kết quả nghiên cứu nếu áp dụng vào thực tế tại BIDV - CNBP.

- Về phương pháp nghiên cứu: Nghiên cứu được tiến hành trong thời gian tương đối ngắn vì vậy nhóm tác giả chưa thể tổng hợp, đánh giá khách quan và đầy đủ về các yếu tố ảnh hưởng đến sự hài lòng của khách hàng cá nhân, như: Yếu tố sự nổi trội (Võ Thanh Hải và cộng sự, 2017), yếu tố thái độ của nhân viên (Nguyễn Ngọc Chánh, 2018).

- Về khảo sát các sản phẩm dịch vụ tại BIDV - CNBP: Nhóm tác giả khảo sát những sản phẩm bán lẻ chính của BIDV - CNBP, chưa bao quát được hết tất cả các sản phẩm dịch vụ tại BIDV - CNBP.

Hướng nghiên cúu tiếp theo: Sau quá trình thực hiện nghiên cứu này, nghiên cứu của nhóm tác giả cũng đã giải đáp được một số vấn đề trong mục tiêu nghiên cứu đã đề ra. Tuy nhiên vẫn còn một số hạn chế nhất định mà nhóm tác giả đã nhận ra trong nghiên cứu này, đó cũng là một số hướng nghiên cứu tiếp theo mà nhóm tác giả sau này thực hiện có thể xem xét để để mang lại những kết quả nghiên cứu tốt hơn. Một số hướng nghiên cứu tiếp theo có thể thực hiện như:

- Có thể xem xét và bổ sung thêm một số yếu tố có ảnh hưởng đến sự hài lòng của khách hàng cá nhân đối với chất lượng dịch vụ, như: Yếu tố sự nổi trội (Võ Thanh Hải và cộng sự, 2017) hay yếu tố thái độ của nhân viên (Nguyễn Ngọc Chánh, 2018).

- Có thể thực hiện việc lấy mẫu theo phương pháp xác xuất để có thể mang lại tính đại diện cao hơn. Những nghiên cứu tiếp theo nên được tiến hành với kích cỡ mẫu lớn hơn nhằm mang lại tính khách quan, ý nghĩa và phản ánh được tính đại diện cao hơn.

- Mở rộng nghiên cứu, khảo sát các sản phẩm dịch vụ bán lẻ mới của BIDV - CNBP.

\section{TÀI LIỆU THAM KHẢO}

[1] BIDV. (2019). BIDV nhận giải thưởng "Ngân hàng cung cấp dịch vụ ngoại hối tốt nhất Việt Nam". Truy cập: https://www.bidv.com.vn/bidv/tin-tuc/tin-ve-bidv/giai-thuong-cung-cap-dich-vu-ngoai-hoi-tot-nhat-viet-nam, 06/08/2019.

[2] BIDV. (2019). BIDV được bình chọn là "Ngân hàng bán lẻ tốt nhất Việt Nam" năm thứ 5 liên tiếp. Truy cập: https://ub.com.vn/threads/bidv-duoc-binh-chon-la-ngan-hang-ban-le-tot-nhat-viet-nam-nam-thu-5-lientiep.257945/, 23/3/2019.

[3] BIDV. (2019). Báo cáo kết quả kinh doanh năm 2018, kế hoạch kinh doanh năm 2019.

[4] Lewis, B. R., \& Mitchell, V. W, Defining and measuring the quality of customer service. Marketing Intelligence \& Planning, 1990, vol. 8, no. 6, pp.11-17.

[5] Advardsson et al, Quality of Service: Making it Really Work (McGraw-Hill Quality in Action). Boston: McGraw-Hill, 1994). 
[6] Parasuraman A, Zeithaml V,\& Berry L. A conceptual model of service quality and its implications for future research. Journal of Marketing, 1985, vol.49, pp.41 - 50.

[7] Svensson, G, A Triadic Network Approach to Service Quality. Journal of Service Marketing, 2002, vol. 16, no. 2, pp. 158 - 179.

[8] Koler. Philip, Quàn trị tiếp thị (bản dịch). TP.HCM: Nhà xuất bản Thống kê, 2011.

[9] Brown, P. F. et al, Class-based n-gram models of natural language. Computational Linguistics, 1992, vol. 18, no. 4 , pp. $467-479$.

[10] Dr. Snehalkumar H Mistry, Measuring customer satisfaction in banking sector: With special reference to banks of Surat City. Asia Pacific Journal of Marketing \& Management Review, 2013, vol. 2, no. 7, pp. 132 140.

[11] Anas Salman Alabboodi, The effect of customer satisfaction on service quality: The case of Iraqi banks. International Journal of Applied Research, 2019, vol. 5, no. 1, pp. 146 - 152.

[12] JJ Navaratnaseelan và P. Elangkumaran. (2014). Impact of Servıce Qualıty on Customer Satısfactıon: A Study on Customers of Commercial Bank of Ceylon PLC Trincomalee District. Reshaping Management and Economic Thinking through Integrating Eco-Friendly and Ethical Practices Proceedings of the 3rd International Conference on Management and Economics, 26 -27, February, 2014.

[13] Võ Thanh Hải và cộng sự (2017). Sự hài lòng của khách hàng về chất lượng dịch vụ tại Ngân hàng Thương mại cổ phần Sài Gòn - Chi nhánh Đà Nẵng. Truy xuất từ: http://tapchicongthuong.vn/bai-viet/su-hai-longcua-khach-hang-ve-chat-luong-dich-vu-tai-ngan-hang-thuong-mai-co-phan-sai-gon-chi-nhanh-da-nang48463.htm

[14] Trần Thị Thanh Thuý (2018). Chất lượng dịch vụ ngân hàng của các Ngân hàng thương mại Việt Nam. Luận án Tiến sỹ, trường Học viên Ngân Hàng.

[15] Hà Văn Dũng, Ảnh hưởng của chất lượng dịch vụ đến sự hài lòng khách hàng cá nhân tại các ngân hàng thương mại. Tạp chí Tài chính, 2019. Vol.1, no. 708, 99-103.

[16] Phạm Xuân Thành. (2018). Các yếu tố ảnh hưởng đến mức độ hài lòng của khách hàng cá nhân về chất lượng dịch vụ ngân hàng Vietinbank chi nhánh Đồng Tháp. Treuy cập: http://tapchicongthuong.vn/bai-viet/cac-yeuto-anh-huong-den-muc-do-hai-long-cua-khach-hang-ca-nhan-ve-chat-luong-dich-vu-ngan-hang-vietinbankchi-nhanh-dong-thap-51814.htm..

17 Lê Thị Thu Hồng và cộng sự. (2014). Đánh giá sự hài lòng của khách hàng đối với Chất lượng dịch vụ thẻ thanh toán của Vietinbank - Chi nhánh Cần Thơ. Tạp chí Khoa học Truờng Đại học Cần Thơ, 33, 21 - 28. 